\title{
Cartography of the Phenomenon and the Phenomenon as Cartography
}

\author{
Guilherme Riscali \\ Universidade de Lisboa \\ guilherme.riscali@gmail.com
}

\begin{abstract}
This paper discusses Gilbert Ryle's image of philosophy as cartography in an attempt to explore the idea of a cartography of the phenomenon, confronting it with the sense it takes in Edmund Husserl's transcendental phenomenology. Ryle tries to grasp the particularity of philosophical tasks as being about specific sorts of problems, not about specific sorts of objects. What is required both of a cartographer and of a philosopher is, according to him, to look at familiar spaces in wholly unusual terms. Husserlian phenomenology then, with its rediscovery of consciousness as an absolute, unbounded field, meets quite well this demand. The uncovered field of the phenomena is not a new region, opposing that of the objects as faced in the natural attitude. It is rather a completely different attitude, just as a map is not a share of the world, but a distinct orientation towards it. The phenomenon, therefore, would not be something that is there to be cartographed as much as a kind of cartography itself. A phenomenological cartography, however, is one that has its specific marks, different from those of the Rylean conception.
\end{abstract}

Keywords: Phenomenon, Cartography, Attitude, Husserl, Ryle

Given the many roads through which phenomenology has followed since its first conception by Edmund Husserl, one could be at a loss as to what, if anything, constitutes its unity and its actual field of study. The very concept of phenomenon and its systematic function in phenomenology have frequently become the matter of much controversy both between interpreters of Husserl and contemporary phenomenologists. Faced with perplexity, one could try and 
map the uses of the concept of phenomenon, as it would appear in many philosophical traditions and even in the many phases of Husserl's thought. $\mathrm{He}$ would then end up with something like a census of its multiple uses and, luckily, with a delimitation, even if a vague one, of what in fact are these phenomena that phenomenology purports to study.

Not failing to recognize the importance of this kind of statistical approach, I would nevertheless suggest that the real question to be asked is rather a different one: namely, whether the phenomenon, as first unveiled in Husserl's transcendental phenomenology, is something there can be a cartography of. Can we speak of an actual cartography of the phenomenon? The reason I think the question is interesting is because it lends itself to arguing that the phenomenon itself is not something that is there to be cartographed as much as it is a cartographical mechanism, that whose systematic function is to allow for a cartography of the phenomenological type. Better than to speak of a cartography of the phenomenon, in this sense, would be to speak of a cartography as accomplished by means of the phenomenon or, briefly, to speak of the phenomenon as a type of cartography. More than being a good subject of cartography, phenomenology could itself be portrayed as decent cartography.

I do believe that shedding some light on this image of philosophical cartography could be useful to center on some aspects of phenomenological philosophy and even to help us better orient ourselves in relation to the special position phenomenology will occupy as a science. A metaphor, after all, is useful not solely where it works, but might be more profitable indeed where it fails, where it shows itself as absurd and finally highlights important inflections of our subject that we did not observe when we first conceived it as a metaphorical image. Thus, to specify even further our initial question, one could ask: how far can we get by speaking of the phenomenon as cartography? To follow that thought all the way down to its consequences is precisely what I will try to do, until it may no longer be followed.

\section{The Rylean notion of cartography}

I would like to take Gilbert Ryle's treatment of philosophical cartography as a way to start our own inquiries. Surely an Oxfordian philosopher like Ryle is 
very dissimilar in style to Husserl, and their plans will certainly diverge in important points, but still what essentially matters is that both have been profoundly concerned with at least one common problem. They have tried to account for the fact that we can navigate the world in different manners and orient ourselves in it in different, though not incompatible and - more important - not rivaling, ways. The Rylean notion of cartography aroused in response to this very problem, and it does seem reasonable to remember him when trying to develop our cartographical account of phenomenological philosophy ${ }^{1}$.

What kind of problem does one face when one decides to become a cartographer? Ryle invites us to suppose the situation of a person who has lived in the same village for years. He can naturally and ordinarily find his way around his village and answer many question about the locations of places there. If, however, he is asked to draw a map of the village, which is later to be joined with other maps of adjacent areas in a more general cartographic effort, he might have trouble doing it.

He is being asked to think about his own familiar terrain in a way that is at the start entirely strange, despite the fact that every item that he is to inscribe or identify in his map is to be something that he is entirely familiar with. In the morning he can walk from the church to the railway station without ever losing his way. But now, in the afternoon, he has to put down with compass bearings and distances in Kilometers and meters the church, the railway station and the paths and roads between. ${ }^{2}$

It happens that this villager, when doing cartography, had to think about the same world in very untypical terms. What is strange to him is not the place he has to describe but rather the radically different description of this place that is asked of him. The villager does not need to be, and must not be, an explorer to be a cartographer - here is Ryle's most clever insight. His work is not one of

\footnotetext{
${ }^{1}$ One could also point to the fact of Ryle's knowledge and admiration - at least for some of his life - for Husserl's work. It is an open question, though, what is the actual extent of this influence on Ryle's own thought.

2 Ryle, G., "Abstractions", in Collected Papers - Vol. 2 - 1929-1968. London: Routledge, 2009, p. 454.
} 
getting to know places he did not know before. It is not a matter of knowing different things so much as one of knowing things differently.

The metaphor is to help us understand exactly what sort of difficulty is in play when we set upon philosophical tasks. It suggests that the philosopher's problem is not unlike the cartographer's and it highlights what is arguably Ryle's philosophical motto: that philosophical problems are not problems about a specific, singular kind of objects, but a specific, singular kind of problems about objects. This cartographical metaphor allowed him to superpose philosophical tasks and ordinary tasks, thus giving philosophy something to do without having to invent mysterious kingdoms or intricate realms for the philosopher to explore. Ryle speaks indeed of philosophical concepts as interdepartmental notions ${ }^{3}$, and of philosophical tasks as the necessarily systematic investigations of the extensions and cross-bearings of these concepts.

However forcibly a man may, in the morning, argue on this or that concrete topic, he may still need to learn a quite new kind of lesson, namely how, in the afternoon, to assess the forces of those arguments and how to compare and correlate them with the forces of seemingly interfering or cooperating arguments. (Ryle, 2009: 457)

We can, in the morning, naturally carry out many concrete, isolated tasks involving concepts such as time or chance or multiplicities. We can measure and predict occurrences in time, we can calculate the probabilities of events with a fair degree of exactitude, we can perform mathematical operations and get away with most of it. But however fine we can use these concepts in our ordinary tasks, we will inevitably have trouble giving a more definite, general account of even the simplest of them, or using them to solve deeply abstract tasks and limit cases - those which involve, for example, strangely large spams of time or unimaginably big numbers.

We start bumping here into the peculiarities of philosophical tasks. These are higher-order operations upon the concepts that we use in ordinary tasks. They are general, abstract and neutral operations:

${ }^{3}$ See "Abstractions" in Ryle (2009: 453). 
We should notice that part of what perplexes the villager when for the first time asked to draw or to read a map of a place in which he is entirely at home is that he has to describe it in perfectly general, cartographical terms - terms, that is, which are shared by all other places. Where he normally thinks of his home, his church and his railway station in personal terms, now he has to think of them in impersonal, neutral terms. For him his village is unlike every other village in being the centre of his own life; but the map is neutral as between his village and any other. (Ryle, 2009: 454)

These are operations utterly dissimilar, attitudes ultimately distinct towards the world. The cartographer has to look to his world while at the same time suspending what was particularly important to him, that towards which he normally gravitates.

Now, one could go on living an entire life of task-filled mornings without just as much as touching philosophical questions in the afternoon. What would this person miss, after all? What do we gain anyway by postprandial reflection on what we just did in the morning?

According to Ryle, we get the possibility of faring our explanations of all those different parts of the world one against another. Precisely as a map allows us to confront our various particular, concrete and personal orientations in a more general plan, so a conceptual cartography allows us to go beyond the singular explanations of things in the world, and to understand the crossbearings of our diverse, sometimes even contradictory ways of talking about them. It allows us to analyze our use of concepts and to identify the points where either these uses clash with one another or one concept extends beyond what would be its correct field of application, thus guiding us to a more elemental knowledge of such notions ${ }^{4}$.

\section{The phenomenological orientation}

My point now should not come as a surprise: many of the concerns that appear on Ryle's notion of cartography are also at work in Husserl's motivations for

\footnotetext{
${ }^{4}$ The most ostensive example of this method is found in what has become Ryle's bestknown work, The Concept of Mind.
} 
his phenomenological project. Just as Ryle clearly detached the examination of principles as an operation distinct from that of their application and presented it as the task of philosophy ${ }^{5}$, Husserl shall take seriously the division of labor between the philosopher and the scientist, who employs scientific methodology to the study of the natural world. He struggles with that all the way from the Logical Investigations, when he clearly defined the program of phenomenological clarification of the subjective conditions of knowledge, to the text of The Crisis of European Sciences, where it will grow as a considerably more complex preoccupation.

It is also importantly present as motivation for Husserl's transcendental project in Ideas I. Though the disjunction there is less straightforward - and the source of many confusions - it is also clear that Husserl takes as a starting point an "unavoidable and important division to be made in the realm of scientific research" (Husserl, 1983: 47 [§ 26]), the division forth from which we will be able to distinguish between the new philosophical science of phenomenology, on the one hand, and dogmatic sciences, on the other. This separation will develop, as we know, into the assumption of a new orientation regarding the world:

[A] new style of attitude is needed which is entirely altered in contrast to the natural attitude in experiencing and the natural attitude in thinking. To move freely in it without relapsing into the old attitudes, to learn to see, distinguish and describe what lies within view, require, moreover, peculiar and laborious studies. (Husserl, 1983: XIX)

This change in attitude has to be something like a constant watch and, hereafter, it must be implied in every single move. After this change, one will not be doing the same tasks as one did before. And the new tasks, curiously, can be described in terms quite akin to Ryle's afternoon philosophical tasks: general, neutral and abstract. Abstract, because they form what Husserl always insists is a science of essences; neutral, since they require the suspension of the world as it was always at hand, in its usual availability to our ordinary living; general, in that the new attitude requires moving away from personal,

\footnotetext{
${ }^{5}$ See also "Philosophical Arguments", in Ryle (2009: 204).
} 
individual perspective. More specifically, it will require an altered regard to be directed upon one's experiences. And this is, in fact, crucial, for it says something about Husserl's specific method in contrast to what we have seen so far of Ryle.

At the start, the modification required by phenomenology had seemed to resonate pretty well with Ryle's cartographical activity. The change in the regime of orientation towards the world allowed us to describe it somehow as cartographical activity. But as we go deeper to consider the actual means of what could be this phenomenological cartography, in its actual operation, many asymmetries begin to spring.

Both Ryle's philosophical cartography and Husserl's phenomenology are projects which thrive on higher-order acts, "acts of the second degree" (Husserl, 1983: 114 [§ 50]), and they have to involve reflection of some kind - they operate "exclusively in acts of reflection" (Husserl, 1983: 174 [§ 77]). Yet it is in the specific character of their reflective operations that we will find decisive disparities. Ryle's method was, as we saw it, talking about ways of talking about things. He got to his conceptual cartography by turning language over itself. This could never be enough for Husserl. Husserl's critique of reason could not be just about linguistic expressions, or about the way we talk about things, or even about judgments alone. The whole originality of phenomenology, as it started to take form in the Logical Investigations, was to never restrict itself to linguistic acts, but to consider all acts of consciousness, in all its rich varieties.

Husserl's reflection on the acts of consciousness had to be more radical than Ryle's linguistic turn. But if it was not simply an analysis of language, it remains to be seen what exactly will be this interior mechanism of cartography of the Husserlian type. This, of course, will be shown in the phenomenological reduction, whose intricate scheme Husserl details in Ideas $I$, but from which it suffices here to emphasize two points, crucial to the image in question.

First, I would like to insist on a specific aspect of this consciousness rediscovered in the phenomenological method of reflecting on experiences. One of the main results of the phenomenological reduction is that it will reveal a consciousness whose boundaries, markedly solid in the natural attitude, are effaced. 
Husserl first stated in The Idea of Phenomenology that immanence was an ambiguous concept - and, following that, also the concept of transcendence. On the one hand, it could be interpreted, as traditionally it was, "in terms of real [reell] containment" (Husserl, 1999: 30) in the act of knowing, but also, on the other hand, it could now be taken to mean that "absolute and clear givenness, self-givenness in the absolute sense" (ibid.) that, after the phenomenological reduction, accompanies every act and their content. By working on these diverging extensions of the concepts of immanence and transcendence, Husserl will conclude that this sphere of immanent things in the sense of absolute givenness is not restricted to what is immanent in the first sense.

The absolute givenness proposed by Husserl will force us to reconsider the partition between consciousness and the world and ultimately to eliminate the gap that skepticism had imposed amid them. This new transcendental subjectivity is to grow beyond Cartesian limitations, beyond the traditional separation of subject and object, and into an "infinite field $[\ldots]-$ the fundamental field of phenomenology" (Husserl, 1983: 114 [§ 50]). As Carlos Alberto Ribeiro de Moura explains, if "this subjectivity has no longer an exterior to itself, then it is no longer the Cartesian Ego, no longer a share of the world, no longer a region" (Moura, 1989: 183; my translation).

This is what the cartographical metaphor puts into light: that the transcendentally pure consciousness cannot be thought of as simply a region within a space. It is a whole, absolute, unbounded field. And a field that, as we know, will incorporate also the things as they appear to this consciousness.

Secondly, an important change will take place as well in the traditional conception of object. When insisting that things should be reconceived as given in consciousness, Husserl is not simply stating that objects as things independent from consciousness should not be taken into consideration. He is actually arguing that it is an essential feature of every conceivable object that it be given in consciousness: "no 'Object' [Objekt] is conceivable without there also being conceivable multiple intentive mental processes [...] in which 'it,' the Object, is intended to as an identical object" (Husserl, 1983: 314 [§ 131]).

Every object can only be this identical $\mathrm{X}$ point of different intentional acts. It means every object is also subjective, in the sense of having a particular perspective, a subjective signature. Objects are thus conceived as the thing-as- 
they-appear, as phenomena - the term specifically understood as emphasis on their givenness in transcendentally pure consciousness.

What is important to retain now is the change that phenomenology forces into the very conception of phenomenon, the need for which was explicitly put forward by Husserl from the earliest stage of his investigation (Husserl, 1983: XVII).

This is where we find the novelty of the phenomenological phenomenon, as it lies in the center of this new philosophical activity. The phenomenon in phenomenology is not, as the name perhaps misleadingly suggests, simply an appearance as opposed to something else, to an actual thing of which it is an appearance. It is not an object of some sort in opposition to another object of a different sort. It is not a region of appearances as opposed to another region. The counterpart to the absoluteness of transcendentally pure consciousness where things are given is the completeness of phenomena in its givenness.

We come finally to realize that the systematic function of the phenomenon in phenomenology is not to reflect an ontological fracture, but to call attention to and reinforce the phenomenological integration discovered in transcendental subjectivity. It is functionally interesting not because it allows us to go back to the things-as-they-appear but because it does that while manifesting that to go back to the things-as-they-appear is to go back to things - the only things there are to go back to. And it is interestingly functional, in the sense that it is not as much in itself some special thing the phenomenological reduction comes to uncover than it is the distinctive mark of this activity in everything uncovered - the clever combining, in a single mechanism, of that which appears and this appearing itself (Moran and Cohen, 2012: 253).

In this sense, the phenomenon is not the sort of thing that can be cartographed. The phenomenon is not a thing, a collection of things or a space to be cartographed. It is not cartographable but cartographic, in that it is the device by which that phenomenological cartography of ours will operate and the mark that is conveyed in everything thus cartographed. It is somehow the particular character of the map that will thereby result.

This elusive conception of the phenomenon as an operation seems already hinted at by the lack of a stable definition for it in Husserl's text itself (Moran and Cohen, 2012: 252). And the difficulty of pinpointing it had already been keenly noted by Eugen Fink when he took the concept of phenomenon as the 
foremost example of what he called an "operative concept" - one that is used more than it is thematically clarified (Fink, 1981: 69) - and indeed as expressing a systemic tension in Husserl's thought between concepts which can and cannot be thematised ${ }^{6}$. By following the question of the cartography of the phenomenon we were stealthily led back, it seems, to what is in fact an original problematic of phenomenological philosophy, with considerable consequences.

\section{Phenomenological cartography}

Even if it evades being cartographed, or precisely because of that, this problematic fixing of the phenomenon in phenomenology grants it that "unique position" as a science - of which Husserl will speak in the opening lines of Ideas I. To comprehend this unique position is an endeavor closely related to our cartographical images. For exactly what we saw could compose a "phenomenological cartography" was the absoluteness of transcendental subjectivity as a field and the inescapable oscillation of the phenomenon as an operating concept. In both figures, we have seen it, there is a challenge to the shape of phenomenology as a region, there is a moving towards its being "metaregional", as Andrea Staiti puts it (2015: 7). From this expression - which is a bit more interesting than "inter-departmental" - one can immediately deduce at least three related ideas: that phenomenology is not a new region; that it does not border other regions; that it is something at another level altogether. All the three of them have cartographical implications that must be scouted.

The first of these characteristics is also that from which the explorer can be distinguished from the cartographer. The former has the adventurous task of discovering new territories, and is guided by the belief that what matters in the end is to simply go to places, the world presenting itself to those who first reach it. The other's duty, subtler and plausibly more imperative, is to make sense out of the world, as familiar as it may be.

Husserl's own ambitions as an explorer were already explicitly debated and put into question. Nicolas De Warren, for instance, notices that

\footnotetext{
${ }^{6}$ It might be worth to remember that something which is not a theme is - as per its Greek roots - something which is not posed, not positioned, not located. Something that, like a shadow, has no proper place.
} 
phenomenology's job is much more complicated than the mere discovery of a new land (De Warren, 2015: 229). Its objects are not inert, are not there to be uncovered. And as Husserl himself says, in a more economical passage, there is no "wealth of salient data" (Husserl, 1983: 147 [§ 63]) available for us in phenomenological orientation. They have to be disclosed in a special sense, constituted by the phenomenological inquiry through attentive reflection and structuring of problems (De Warren, 2015: 229-230). It is as such closer to drawing a map, job to which the phenomenologist seems fitter, and to which Ryle, reasonably, seemed already more inclined - in his example, we have seen it, one had become a cartographer without ever leaving one's village. Here again as before, the phenomenologist's problem is not about a special sort of objects so much as it is a special sort of problem about objects: the puzzling problem of both constituting and describing its objects.

In addition, phenomenology does not aim to suggest corrections to scientific methods, to improve the exactness of our measurements or to help predicting natural events more accurately. It does not say anything about the world as taken in the natural attitude. And the fact that it is not competition to the dogmatic sciences should not be taken as the evidence of an opposition to them, just as a map should not be taken as opposition to the world that it maps or as a kind of substitute for it. The dogmatic sciences were not to be erased after the

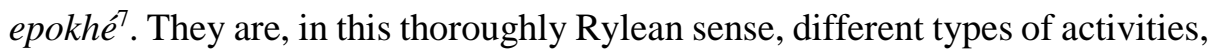
as walking around a village is different from drawing a map of it. Phenomenology does not border other regions, meaning that it does not divide space, nor disputes with other sciences for areas of the natural world which to study. Phenomenology is not to be put side by side with other sciences, in flat surface. It is not, say, "south of psychology" or "right above mathematics". In the same fashion, the pure consciousness of transcendental phenomenology cannot be bounded by the world, just as Almada cannot be bounded by the map of Lisbon. As we have already seen, transcendental subjectivity was a whole and unlimited field in itself. The phenomenological reduction, by changing the

\footnotetext{
${ }^{7}$ This might seem trivial and yet failing to keep both of these things in mind at all times can have uncomfortable consequences for those wandering in the phenomenological orientation.
} 
level of investigation, also overcame the diplomatic question of phenomenology's boundaries.

This shift of level is an approach to the third aspect of its meta-regionality and a clue towards its positive dimension, its unique position. To better grasp it, though, it is of value to say a few things further about what phenomenological cartography cannot be. What kind of map is it that it cannot draw? Well, a Rylean map, for starters. We had seen Ryle's business as being conceptual cartography. Namely, it was a way of talking about the ways of talking about things - which is talking all the way through. It was a map that was linguistic end-to-end. And words do not easily give up their representational power. The result is that Ryle's conceptual cartography produces the philosophical equivalent of a traditional, geopolitical map, representing by means of its peculiar language the objects - countries, administrative regions, borders and the like - which are there at the natural, ordinary level of life.

Nothing could be stranger to phenomenology. Though it is a reflection on the acts of consciousness, the objects which will appear in it are not the same as those in the natural attitude. Phenomenology, as many have noted, does not move inside the scope of representation. And surely the results we get from this phenomenological cartography are not representations. The objects which happen to appear in this map are not the usual objects of the natural world. Husserl makes it clear we will not recreate the "natural sphere of objects" (Husserl, 1983: 148 [§ 63]). Phenomenological cartography should not be Borgesian cartography - a map on a one to one scale is not a good sort of map. This is a critical point in avoiding a mistake that Carlos Alberto Ribeiro de Moura says affected some of Husserl's students: to do phenomenology of everything.

Sartre does not conceal the strong impression caused in him by Raymond Aron's account, who told him that in Germany, then swayed by phenomenology, one could carry out the 'description' of a glass on top of a bar table, - and that was... 'philosophy'! Likewise, literature of that time did not spare us of endless, humdrum pages, "describing" in all its details, presumably infinite, a 'concrete' doorknob. But what would Husserl have to do with all of this? Positively nothing. (Moura: 2006, 17-18; my translation) 
All of this leads to what seems an insurmountable chasm between cartography of the Rylean, conceptual type and of the Husserlian, phenomenological one, in spite of the common points already remarked, and it makes an identification of their projects much trickier.

John K. O'Connor, for example, in a paper considering the influence of Husserl on Ryle, pointed to Husserl's constant worry about mistakes of "categorical confusion" (O'Connor, 2012: 239) and about the metabasis, a major methodological trap, the avoidance of which would lead to many of his original philosophical unfoldings. This approximation is significant and reinforces the idea of a shared set of preoccupations between both philosophers. Yet to say, as he will thereafter, that the phenomenological reduction is "a methodological procedure designed to insulate philosophy against a pervasive category mistake" (O'Connor, 2012: 240) does sound like an overstatement. The category mistake in question is that, already discussed, of the double senses of the concepts of immanence and transcendence, as presented in The Idea of Phenomenology, and O'Connor suggests that the essential role of the reduction was then the evasion of that most treacherous metabasis of all, between immanence in the traditional and in the phenomenological sense ${ }^{8}$.

While we saw quite well that the phenomenological reduction does deal with that question, still for certain it cannot stop there. It cannot be some conceptual cartography for dummies - one with only two concepts whose boundaries it has to determine. Conceptual cartography had as its proper function to avoid category mistakes, but this is to be to the phenomenological reduction merely the first move in order to start the actual phenomenological work, an

8 It is interesting to note the opposite directions phenomenology and Rylean cartography took in dissolving the traditional concept of mind. While Ryle effectively emptied the concept, breaking it down and collapsing the traditional mental occurrences into various types of activities or behaviors, Husserl enlarged it until it overcame the traditional, Cartesian separation by gaining to the unified whole of transcendental subjectivity. If Ryle relied heavily in boundaries, Husserl did away with them. Instead of looking for the cross-bearings between immanence and transcendence, between mind and world, Husserlian phenomenology "dissolves" the problem, as Connor puts it, into transcendental consciousness. 
undertaking that shall not be exhausted at the immediate realization of the absoluteness of transcendental consciousness.

The Rylean metaphor of cartography does seem to enlighten us as to the motivations of transcendental phenomenology, to the general character of philosophical activity in Husserl, and to the need of a unique position in which to situate phenomenology. But it had not done so well in spelling out the specificity of its method and it will not prosper in showing with clarity what its particular dimension could be. If we want to proceed with the cartographical metaphor, this is the point to part ways with its Rylean configuration and, modifying it thoroughly, accept a radical new cartographical model, of completely different means and results.

While Ryle's linguistic map, plotting in the level of language, had a flattening effect, and resulted in something of a surface map, the only possibility for a phenomenological cartography is to secure its unique position deeper underground. If its objects could not be those of the natural world, that is because its task is a reflection upon the acts of consciousness in the search specifically for its elemental structures that are not superficially apparent, and whose description is the vocation of eidetic sciences such as phenomenology. This can only be then a sort of topographic map, a map of landforms, singular in that it grasps the essential shape of the terrain, that which constitutes its fundamental grounds, the geological structure - an image the drawing of which is more appropriate to describe the results of the investigations into the constituted and constituting field of transcendentally pure consciousness.

This position attends the demand of priority that will be necessary for phenomenology to become the "meta-regional critique of reason" (Staiti, 2015: 7) it is destined to be. Situated somehow prior - geologically at least - to the ramification of science into separate regions, phenomenology can be the field of those gentle yet steady underlying essential structures upon which knowledge may be founded. This underground meta-regionality is just the dimension it needs as a scientific theory of knowledge, as the examination of the

skeptical problems of the possibility of knowledge which are directly resolved into the universality of principles so that, by applying to the solutions acquired, the consequences for judging about the ultimate sense and cognitive value of the results of the dogmatic sciences can be drawn. (Husserl, 1983: 48 [§ 26]) 
Phenomenology, therefore, cannot be defined as a tranquil postprandial philosophy, like Ryle's conceptual cartography was. There, it was a matter of a clear precedence of the morning, natural tasks over the philosophical ones, temporally but also logically: Ryle's higher-order tasks were plottings of his natural tasks. Husserl, for his part, while holding that natural tasks were prephilosophical (Husserl, 1983: 47), and talking about their priority over philosophical and epistemological investigations in a temporal or historical sense cannot hold that relation for much longer than that. In fact, for him, philosophical tasks not only do not depend on any specific natural task, but if there is any relation between them at all, it is one of epistemological priority of the philosophical tasks.

What is dawning here is maybe the most challenging and significant question of the phenomenological endeavor. It is a question about which Husserl's positions seem to vary at times, one that he admits poses serious problems and controversies (Husserl, 1983: 366 [\$ 153]) and that will mark the unfinished enterprise of the second and third volumes of Ideas to finally become progressively more sophisticated as Husserlian philosophy matures. It is the question of the actual, functional relation to be established between phenomenology and all the other sciences.

The issue seems to be the reconciling of what was presented in a first moment as the most radical divorce only to wind up in the project of ultimately some reunion. We have seen phenomenology carved to a marked, incongruent domain and were taught to proceed from the space opened between it and traditional scientific discourse. And yet Husserl suggests now a strong foundational relation among them. Does that innovative chthonic space inaugurated by phenomenology possibly host the roots of our old cartesian tree? It is this unsettling position of phenomenology as "first" philosophy (Husserl, 1983: 148 [ $\$ 63]$ ) that threatens all attempts so far of capturing it in a metaphorical image. What for could be a map such as this? A topographic map is probably not the one to use when lost and trying to find a way back into familiar territories. Can it provide guidance enough in order to rebuild something from the most basic, structural layers and to serve as foundation to the sense and cognitive value of dogmatic sciences? Or is this - as perhaps Ryle would have put it - the problem of reading the map south-up? 


\section{Bibliography}

DE WARREN, N. (2015). «Concepts without pedigree: The noema and neutrality modification». In: Andrea Staiti (ed.). Commentary on Husserl's "Ideas I". Berlin: De Gruyter, 225-255.

FINK, E. (1981). «Operative concepts in Husserl's Phenomenology». In: Apriori and World. European Contributions to Husserl's Phenomenology. The Hague: Martin Nijhoff, 56-70.

HuSSERL, E. (1999). The Idea of Phenomenology. Trans. L. Hardy. Dordrecht: Kluwer.

- (1983). Ideas Pertaining to a Pure Phenomenology and to a Phenomenological Philosophy. Trans. F. Kersten. The Hague: Martinus Nijhoff.

MorAn, D. and J. COHEN, J. (2012). The Husserl Dictionary. London: Continuum.

MourA, C. A. R. (2006). «Prefácio». In: Ideias para uma Fenomenologia Pura e para uma Filosofia Fenomenológica. Trad. M. Suzuki. Aparecida: Ideias e Letras, 15-23.

- (1989). Crítica da Razão na Fenomenologia. São Paulo: Nova Stella/EDUSP.

O'ConNOR, J. K., «Category Mistakes and Logical Grammar: Ryle's Husserlian Tutelage». Symposium, 16 (2), 235-250.

RYLE, G. (2009). Collected Papers. Vol. 2: 1929-1968. London: Routledge.

StAiti, A. (2015). «Introduction». In: Andrea Staiti (ed.). Commentary on Husserl's "Ideas I". Berlin: De Gruyter, 1-12.

GUILHERME RisCALI holds a B. A. in Philosophy from the University of São Paulo (2013). He currently attends the seminars in the M.A. Program in Philosophy at the University of Lisbon, where he also takes part in the Research Group «Line of Research in Phenomenological Thought» of the Center of Philosophy of the University of Lisbon (CFUL). His research focuses on the phenomenology of Edmund Husserl, in particular the questions it raises in the fields of philosophy of language and philosophy of history. 